\title{
The Thermal Radiation of the Atmosphere and Its Role in the So-Called Greenhouse Effect
}

\author{
Thomas Allmendinger \\ Independent Scholar, Zunstrasse 1, CH-8152 Glattbrugg, Switzerland \\ Email: inventor@sunrise.ch
}

How to cite this paper: Allmendinger, T. (2018) The Thermal Radiation of the Atmosphere and Its Role in the So-Called Greenhouse Effect. Atmospheric and Climate Sciences, 8, 212-234. https://doi.org/10.4236/acs.2018.82014

Received: March 5, 2018

Accepted: April 23, 2018

Published: April 26, 2018

Copyright $\odot 2018$ by author and Scientific Research Publishing Inc. This work is licensed under the Creative Commons Attribution International License (CC BY 4.0).

http://creativecommons.org/licenses/by/4.0/

c) (i) Open Access

\begin{abstract}
Knowledge about thermal radiation of the atmosphere is rich in hypotheses and theories but poor in empiric evidence. Thereby, the Stefan-Boltzmann relation is of central importance in atmosphere physics, and holds the status of a natural law. However, its empirical foundation is little, tracing back to experiments made by Dulong and Petit two hundred years ago. Originated by Stefan at the end of the $19^{\text {th }}$ century, and theoretically founded afterwards by Boltzmann, it delivers the absolute temperature of a blackbody-or rather of a solid opaque body $(S O B)$ - as a result of the incident solar radiation intensity, the emitted thermal radiation of this body, and the counter-radiation of the atmosphere. Thereby, a similar character of the blackbody radiation-describable by the expression $\sigma \cdot T^{4}$-and the atmospheric counter-radiation was assumed. But this appears quite abstruse and must be questioned, not least since no pressure-dependency is provided. Thanks to the author's recently published work-proposing novel measuring methods-, the possibility was opened-up not only to find an alternative approach for the counter-radiation of the atmosphere, but also to verify it by measurements. This approach was ensued from the observation that the IR-radiative emission of gases is proportional to the pressure and to the square root of the absolute temperature, which could be bolstered by applying the kinetic gas theory. The here presented verification of the modified counter-radiation term $A \cdot p \cdot T^{0.5}$ in the Stefan-Boltzmann relation was feasible using a direct caloric method for determining the solar absorption coefficients of coloured aluminium-plates and the respective limiting temperatures under direct solar irradiation. For studying the pressure dependency, the experiments were carried out at locations with different altitudes. For the so-called atmospheric emission constant $A$ an approximate value of $22 \mathrm{Wm}^{-2} \mathrm{bar}^{-1} \mathrm{~K}^{-0.5}$ was found. In the non-steady-state, the total thermal emission power of the soil is given by the difference between its blackbody radiation and the counter-radiation of the atmosphere. This relation explains to a considerable part the fact that on mountains the atmos-
\end{abstract}


pheric temperature is lower than on lowlands, in spite of the enhanced sunlight intensity. Thereto, the so-called greenhouse gases such as carbon-dioxide do not have any influence.

\section{Keywords}

IR (Infrared) Radiation of Gases, Thermal Radiation of the Atmosphere, Albedo, Solar Adsorption Coefficient, Radiation Equilibrium, Limiting Temperature

\section{Introduction}

Thermal and IR-radiative measurements at gases encounter several principal difficulties: Firstly, gases need to be embedded in a vessel from a solid material which may considerably influence and overlay the thermal behaviour due to its higher heat capacity. Secondly, thermal-radiative energy transfer-i.e. electromagnetic interaction-may be influenced by simple heat conduction as well as by gas convection. And thirdly, the coexistence of radiative energy and of heat energy complicates the situation since one component may be partly converted into the other, and vice versa. Thereby it has to be realized that heat energy is due to atomic or molecular translational motion, rotation and nuclear vibration, while radiative energy is due to electronic oscillations at atoms or molecules. The first aspect concerns thermodynamics, implying non-quantized processes, while the second aspect affects quantum mechanics and thus energetically quantized processes. Planck's distribution law bridged the two domains applying the coherence between temperature and entropy [1] [2] [3]. However, it is confined to boundary conditions, for instance to equilibrium states between emission and absorption intensities. But in particular, it concerns so-called blackbodies, and not implicitly gases. Overall, this domain appears to be the most intricate one in physics-apart from nuclear physics-, calling for considerable expertise, while, on the other hand, it is in everyone's interest in so far as it affects the climate and thus the day-to-day life.

It must be noted that contemporary atmospheric physics is rich in theories and hypotheses but poor in experimental evidence which in fact should deliver the final proof of the truth-and not the credence in authorities, as Robert Boyle claimed already in the $17^{\text {th }}$ century. Notably, the large part of basic radiation experiments was made in the $19^{\text {th }}$ century. In particular, Beer formulated his absorption law for liquids in 1852 (which is not identical with the nowadays assumed absorption law named after him), using an oil-lamp as a light source [4], while Tyndall published in 1861 absorption experiments with carbon-dioxide in comparison to air, using Leslie-cubes as thermal radiation sources, cf. Figure 1 [5]. Stefan, the eponym of the Stefan-Boltzmann Law, did not make own experiments but solely interpreted the results of Dulong and Petit which had already been published in 1817, using the equipment shown in Figure 2 [6] [7]. 


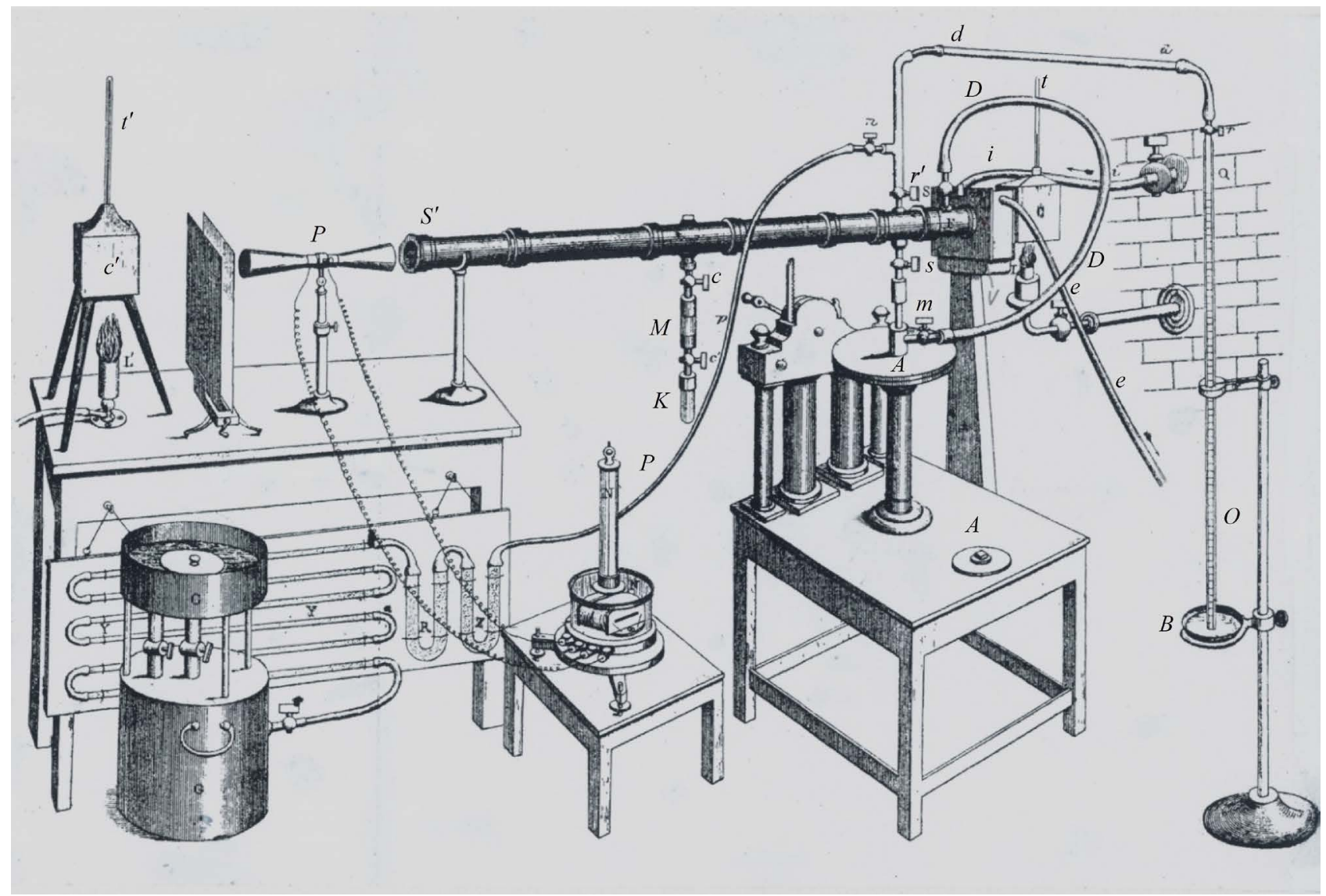

Figure 1. The preferred apparatus of Tyndall.

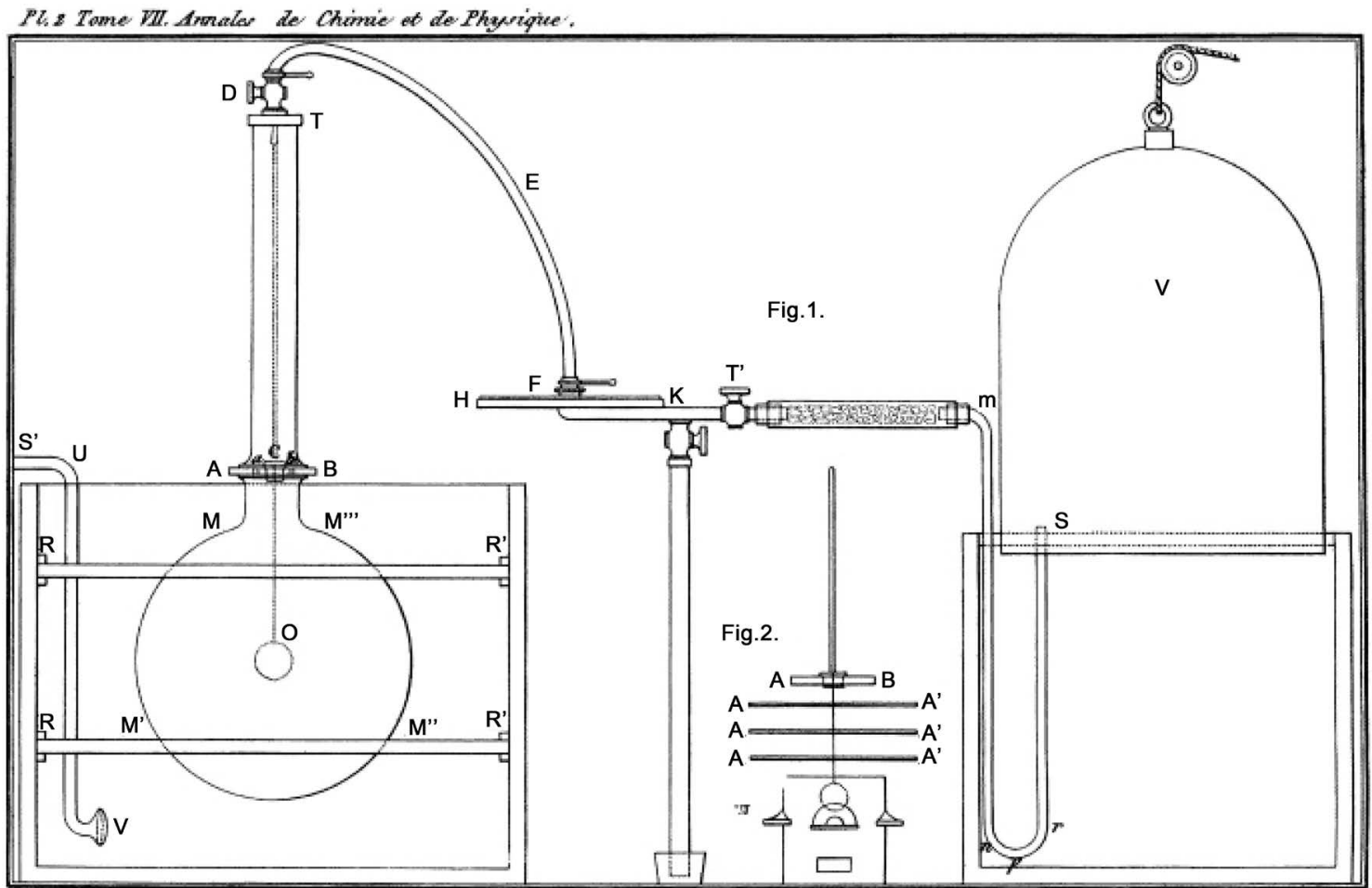

Figure 2. The equipment of Dulong and Petit. 
Lummer and Pringsheim published their empiric results concerning blackbody radiation in 1899 [8] which allowed verifying Planck's quantum theory, established in 1900.

As to these basic experiments, the predominance of photometric and spectroscopic methods is remarkable while caloric methods were still neglected. In fact, the spectroscopic methods are even the only methods which were used in recent research, particularly in connection with satellite measurements. Thereby, the intensity loss of IR-radiation is detected after passing through a medium-in our case a gas, in particular atmospheric air-, while the possible temperature change of the medium is disregarded. But this method exhibits two principal weaknesses which will later be discussed on the basis of the author's recently published work: It is not sure whether-or to which extent-the absorbed radiation is converted into heat. Moreover, very weak radiative absorbance by the gas may be disregarded due to the insufficient sensibility of the apparatus, in spite of the fact that for spectroscopic measurements prisms and lenses are needed which partly absorb IR.

Besides the application in bolometers, the sole method implicating caloric measurements is the one which concerns the Stefan-Boltzmann relation. As already mentioned, Stefan's approach [6] was based on earlier experiments of Dulong and Petit [7], using the equipment shown in Figure 2, while Boltzmann delivered the theoretical explanation five years later [9]. Subsequently, the respective constant could be exactly computed using Planck's theory. The said relation is of central importance in atmosphere physics holding the status of a physical law, even if some doubts are justified. Nevertheless it represents the pivot of the present treatise.

The Stefan-Boltzmann relation comprises three decisive conceptions:

Firstly, it makes use of the radiation law which is valid for blackbodies under vacuum, given by (1):

$$
I=\sigma \cdot T^{4}
$$

where $I=$ radiation intensity $\left[\mathrm{Wm}^{-2}\right], T=$ absolute temperature $[\mathrm{K}]$

The Stefan-Boltzmann constant $\sigma$ can empirically be determined, but-as above mentioned-also theoretically be computed, yielding (2), cf. [10] p. 583:

$$
\sigma=2 \pi^{5} k^{4} / 15 c^{2} h^{3}=5.75 \times 10^{-8} \mathrm{~W} \cdot \mathrm{m}^{-2} \cdot \mathrm{K}^{-4}
$$

where $k=$ Boltzmann constant, $c=$ light velocity, $h=$ Planck constant

Secondly, it is supposed that in the presence of the atmosphere-or of another blackbody-, which is held at a constant temperature $T_{\text {atm }}$, atmospheric counter radiation takes place, which leads to a reduction of the total radiation of the blackbody, yielding the reduced value $I^{*}$ according to (3). Thereby, the same radiation law is assumed for this counter-radiation as for a blackbody:

$$
I^{*}=\sigma\left(T_{\text {blackbody }}^{4}-T_{\text {atm }}^{4}\right)
$$

And thirdly, radiation equilibrium is assumed between the intensities of the incident solar radiation $\Phi$ and the total blackbody radiation (4), implying a 
steady state where a constant limiting temperature of the black body is reached:

$$
\Phi=\sigma\left(T_{\text {blackbody,lim }}^{4}-T_{\text {atm }}^{4}\right)
$$

or rearranged

$$
\sigma \cdot T_{\text {blackbody, lim }}^{4}=\Phi+\sigma \cdot T_{\text {atm }}^{4}
$$

Hence, the Stefan-Boltzmann relation was applied to the whole atmosphere-or rather to its lowest layer-, which obviously does not exhibit any surrounding walls, as it was the case for the measurements of Dulong and Petit. Instead, it is held together by the gravity of the Earth. However, this implies a considerably inhomogeneity-even when cloud and dust effects are neglected-, not only because of the vertical pressure and temperature gradients, but also because of horizontal gradients caused by the ball shape of the Earth, which leads to latitude-dependant solar irradiation intensities. In addition, differences in altitude, due to mountains, as well as diurnal and seasonal fluctuations contribute to permanent but not consistent motions which hardly admit steady-state conditions.

When, instead of a blackbody, a coloured solid opaque body (abbrev. $S O B$ ) is used, these equations can be modified to the Equations ((5a) and (5b)) since the thermal emission power of a coloured solid opaque body turned out to be equal to the thermal emission power of a blackbody [11]:

$$
\Phi \cdot \beta_{\mathrm{s}}=\sigma\left(T_{\mathrm{SOB}, \mathrm{lim}}^{4}-T_{\mathrm{atm}}^{4}\right)
$$

or rearranged

$$
\sigma \cdot T_{\mathrm{SOB}, \mathrm{lim}}^{4}=\Phi \cdot \beta_{\mathrm{s}}+\sigma \cdot T_{\mathrm{atm}}^{4}
$$

yielding formula (6) for calculating the limiting temperature of an irradiated coloured SOB:

$$
T_{\text {SOB }, \lim }=\sqrt[4]{\frac{\Phi \cdot \beta_{s}}{\sigma}+T_{\mathrm{atm}}^{4}}
$$

Therein, $\beta_{s}$ indicates the solar reflection coefficient, expressing the portion of absorbed irradiation. But normally, instead of this solar absorption coefficient, the complementary solar reflection coefficient $\alpha_{s}$ (or the "albedo") is used which entails its indirect determination according to the relation $\beta_{s}=1-\alpha_{s}$. Since this may lead to uncertainties due to scattering of the reflected radiation, a method for the direct determination of the solar reflection coefficient $\beta_{s}$ was developed by the author, measuring the warming-up of coloured solid opaque plates [11]. Thus, it spares you the trouble of determining the albedo and will briefly be described in the next chapter, in particular since it is suitable to empirically assess the Stefan-Boltzmann relation.

In any case it should be realized that the incident solar intensity $\Phi$ and the ambient surface air temperature $T_{\text {atm }}$ are not independent of one another, apart from the fact that the latter one is ill-defined. However, this interdependency is not distinctly computable because of the variety of relevant further parameters 
and processes. Moreover, in reality the limiting temperature of superficial materials is hardly ever reached, not least because of the diurnally alternating altitude of the sun and, in particular, because of the cooling-down of the Earth surface during night. In the latter case, the intensity of the incident solar intensity becomes zero. Instead, a radiative emission of the solid opaque body-representing the soil-is to be anticipated, thus Equation (5b) turns into Equation (7):

$$
\Phi_{\text {emission,soil }}=\sigma \cdot T_{\text {soil }}^{4}-\sigma \cdot T_{\text {atm }}^{4}
$$

However, the cooling-down experiments described in [11] did not verify this equation. As an explanation, the different characters of the two participants have to be taken into account: in the case of solid materials, primarily the properties of the surface are relevant, while in the case of gases the relevant processes occur inside, i.e. within their whole extension range. This means, that the former processes occur two-dimensionally, while the latter ones are three-dimensional. It seems to be obvious that the atmosphere acts altogether incidentally like a solid thermal radiator, suggesting that it behaves like a solid opaque body. However, it can be assumed that, if the atmosphere were less extensive, its back-radiation power would probably be weaker, due to the reduced atmospheric pressure. As a consequence, an alternative approach such as

$$
\Phi \cdot \beta_{\mathrm{s}}=\sigma \cdot T_{\mathrm{SOB}, \mathrm{lim}}^{4}-f\left(p_{\mathrm{atm}}, T_{\mathrm{atm}}\right)
$$

should be taken into consideration, exhibiting the presently unknown term $f\left(p_{\text {atm }}, T_{\text {atm }}\right)$, being a function of atmospheric pressure and temperature, appears reasonable but difficult to derive and verify. It is one of the main goals of this treatise to find a formal expression for this term. The recently reported and below described discovery of near-infrared absorption by gases delivered the key for finding such an expression. Since this novel method and its results cannot be assumed to be generally known, it will be recapitulated in chap. 3. But first of all, the method for the direct determination of the solar absorption coefficient will be described, allowing the empirical verification of the proposed atmospheric term by variation of the atmospheric pressure due to different sea levels.

\section{A Novel Method Suited for the Validation of the Stefan-Boltzmann Relation}

A direct determination method for the solar absorption coefficient has been recently published by the author where the temperature rise of coloured plates in the presence of vertical incidental solar light is measured [11]. The plates were $10 \times 10 \mathrm{~cm}^{2}$ large and normally $20 \mathrm{~mm}$ thick. To avoid heat losses laterally and at the bottom, the plates were embedded in Styrofoam, and covered with a thin transparent foil acting as an outer window to minimize erratic cooling by atmospheric turbulence (Figure 3). The preferred reference material was aluminium. It guarantees a high measurement precision, on the one hand due to its high specific heat capacity, reducing the thermal interference with the mounting 
material, and on the other hand due to its high thermal conductivity facilitating the heat dispersion in the plate and thus minimising the temperature difference between surface and bulk. For comparison, additionally other materials were used (wood, brick, and stone).

For the warming-up experiments several coloured plates were orientated exactly vertically to the incoming sunlight. In order to enable a correct orientation, the plate modules were positioned on an adjustable carrier (Figure 4). The temperatures were measured at regular intervals of 5 minutes using Hg-thermometers being centrally inserted in holes. The heating-rates could easily be determined by graphically assessing the initial slopes of the time/temperature curves. The sky had to be cloudless during the experiment. For detecting the intensity of the solar insolation, a suitable electronic apparatus was used. The time/temperature-plots

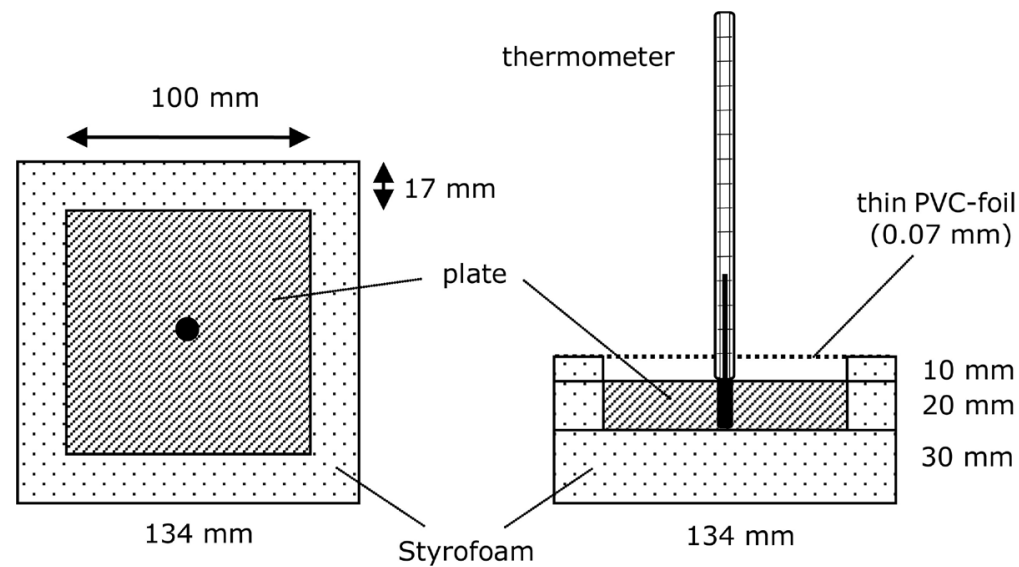

view from above

cross-section

Figure 3. Coloured plate embedded into Styrofoam and covered by a transparent foil.

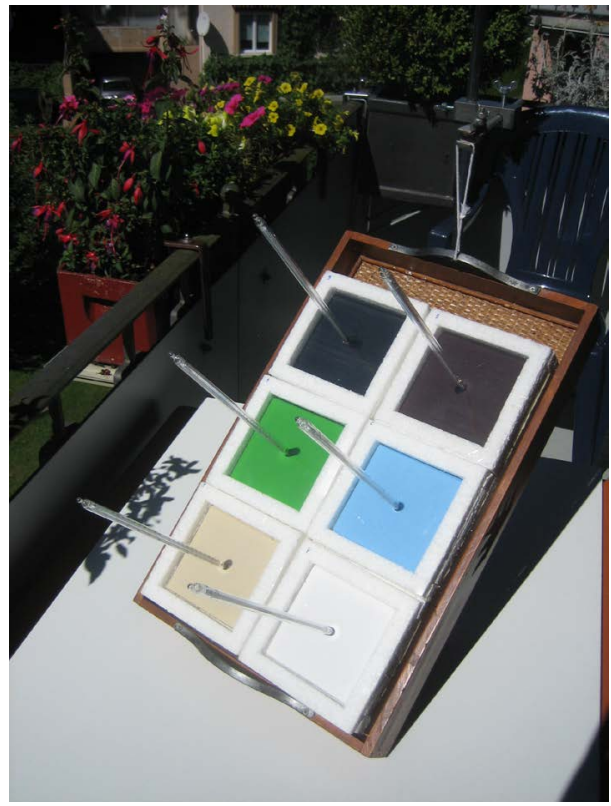

Figure 4. Panel comprising six modules. 
for differently coloured plates are shown in Figure 5. Considering the heat capacities of the plates, the specific solar reflection coefficients $\beta_{\mathrm{s}}$ could be calculated.

As expected, such plates being exposed to direct sunlight will not be warmed up ad infinitum but only up to a limiting temperature. Thus the time/temperature-curves will flatten sooner or later, losing their initially linear character. This phenomenon is already briefly perceptible when, instead of aluminium, plates from wood are inserted which exhibit a lower heat capacity implying a quicker warming-up. Obviously, this can be explained with the emission of thermal radiation effecting cooling-down, since it is temperature dependent, and growing till its intensity is equal to the intensity of the absorbed incident solar radiation.

With the plates used it was not possible to reach the limiting temperature ranges since the measuring period was too short. However, it was possible to study the cooling-down effect separately in a darkened room, using the same embedding as the one which had been used for the warming-up measurements, but starting from an elevated temperature being achieved by preheating the plates in an oven (Figure 6). As expected, the cooling-down rates depended on the material, in particular on its heat capacity. But unexpectedly, they did not depend on the surface colour. This was surprising since it seemed to contradict the well-known theorem of Kirchhoff which states that the absorbency of a surface is equal to its emissivity. However, Kirchhoff s statement was made at a time when, for instance, the quantization of electromagnetic radiation was not yet known [12] [13]. Therefore, the body must not necessarily be black, it is sufficient that it is opaque. Hence, Planck's distribution law is not exclusively valid for blackbodies, but also for any solid opaque body.

As the analysis yielded, the cooling-rates were proportional to the temperature difference between plate and ambient air, leading to exponential curve-courses

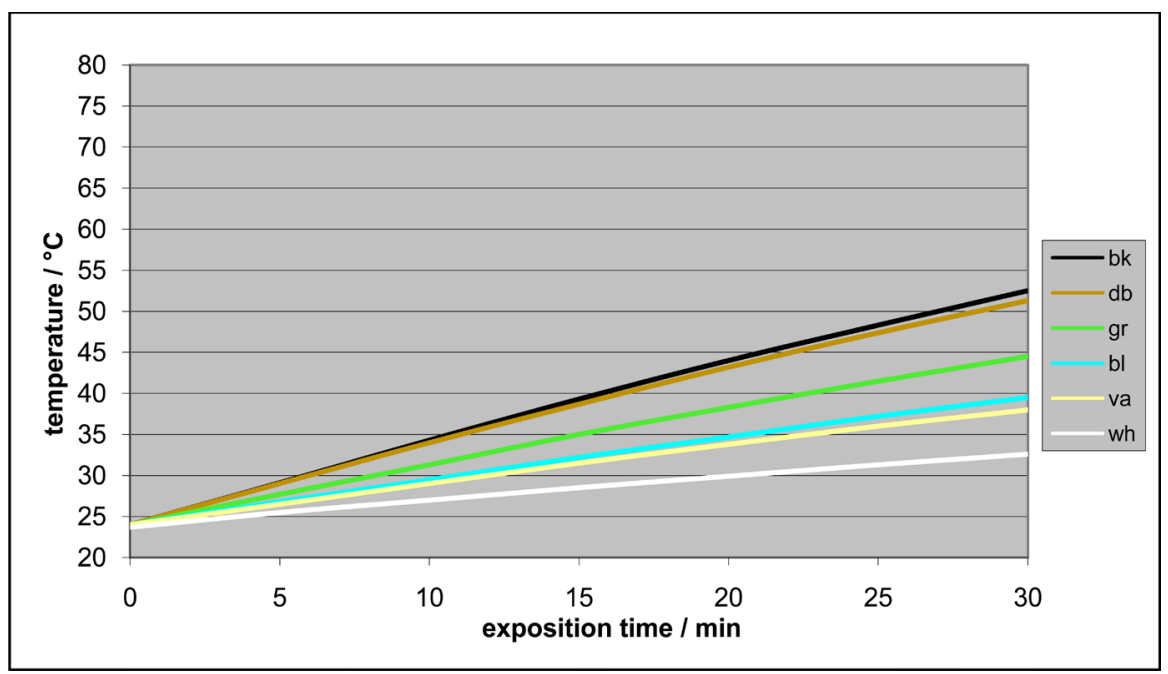

Figure 5. Warming-up of aluminium at $1040 \mathrm{Wm}^{-2}(\mathrm{wh}=$ white, va $=$ vanilla, $\mathrm{bl}=$ blue, gr $=$ green, $\mathrm{db}=$ dark brown, $\mathrm{bk}=$ black). 


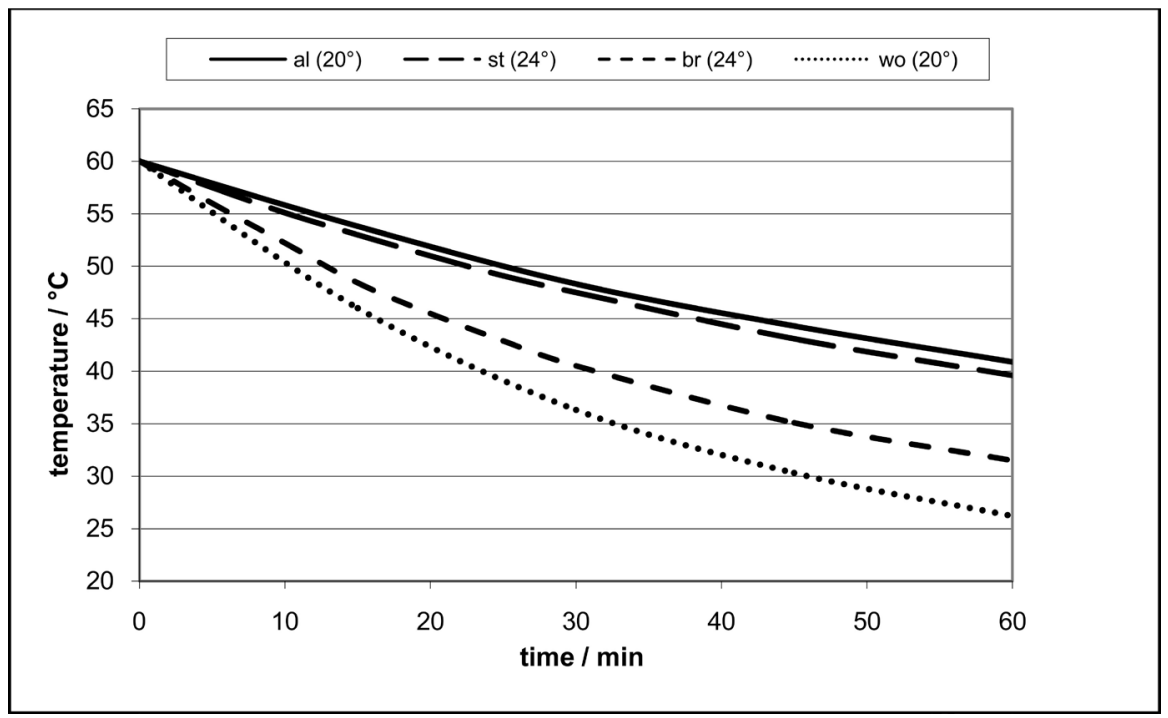

Figure 6. Cooling-down of different materials, with covering foil $(\mathrm{al}=$ aluminum, $\mathrm{st}=$ stone, br = brick, wo = wood; in brackets: ambient temperature).

which were exactly describable with a mathematic formula. It exhibits the so-called heat transfer coefficient $B$ which can be determined from experimental data. It depends on the experimental conditions, in particular on the surrounding atmosphere, but not on the specific properties of the plates. Using the respective apparatus, a general heat transfer coefficient of approx. $9 \mathrm{Wm}^{-2} \mathrm{~K}^{-1}$ was obtained. In the case of the absence of a foil, the heat transfer coefficient increased up to $15 \mathrm{Wm}^{-2} \mathrm{~K}^{-1}$. However, as it seems obvious, the heat conductivity of the material is decisive, too, but scarcely implementable.

Combining the differential equations for the warming-up rate and the cooling-down rate, a differential equation for the overall-process was obtained. Its solution yielded Equation (9):

$$
T=T_{\text {atm }}+\frac{\Phi \cdot \beta_{s}}{B}\left(1-\mathrm{e}^{-\frac{B \cdot a}{m \cdot c_{m}} t}\right)
$$

whereby $a=$ area of the plate, $m=$ mass of the plate, and $c_{m}=$ its mass specific heat capacity.

When $T=\infty, T$ has reached a limes which is computable by Equation (9):

$$
T_{\lim }=T_{\text {atm }}+\frac{\Phi \cdot \beta_{s}}{B}
$$

Hence, according to formula (10), the limiting temperature is independent of the heat capacity, but solely dependent on the irradiation density $\Phi$, the solar absorption coefficient $\beta_{s}$, and the heat transfer coefficient $B$, while the ratio of the limiting temperatures (in ${ }^{\circ} \mathrm{C}$ ) is equal to the ratio of the $\beta_{s}$-values.

Using formula (9), the temperature courses at differently coloured aluminium-plates were calculated applying this model and plotted in Figure 7. Respective plots for similarly coloured plates exhibiting lower heat capacities reveal larger heating rates but identical equal limiting temperatures. Although this 
modelling method cannot deliver exact results since the heating-up and the cooling-down process were not carried out under the same conditions, the results of this modelling appear nevertheless plausible and in principle accurate.

In principle, this method is suitable for verifying the Stefan-Boltzmann relation by comparing the limiting temperatures for different colours using formulas (6) and (10). For that purpose, in Figure 8 the results of the two computation methods are compared for the four colours white, blue, green and black, based on the edge data of the original own measurements quoted in [11]. They are consistent to such an extent that the validity of the Stefan-Boltzmann relation seems to be proved.

However, it should be regarded that the measurements of Dulong and Petit, evaluated by Stefan, were made in closed vessels-and not in contact with the

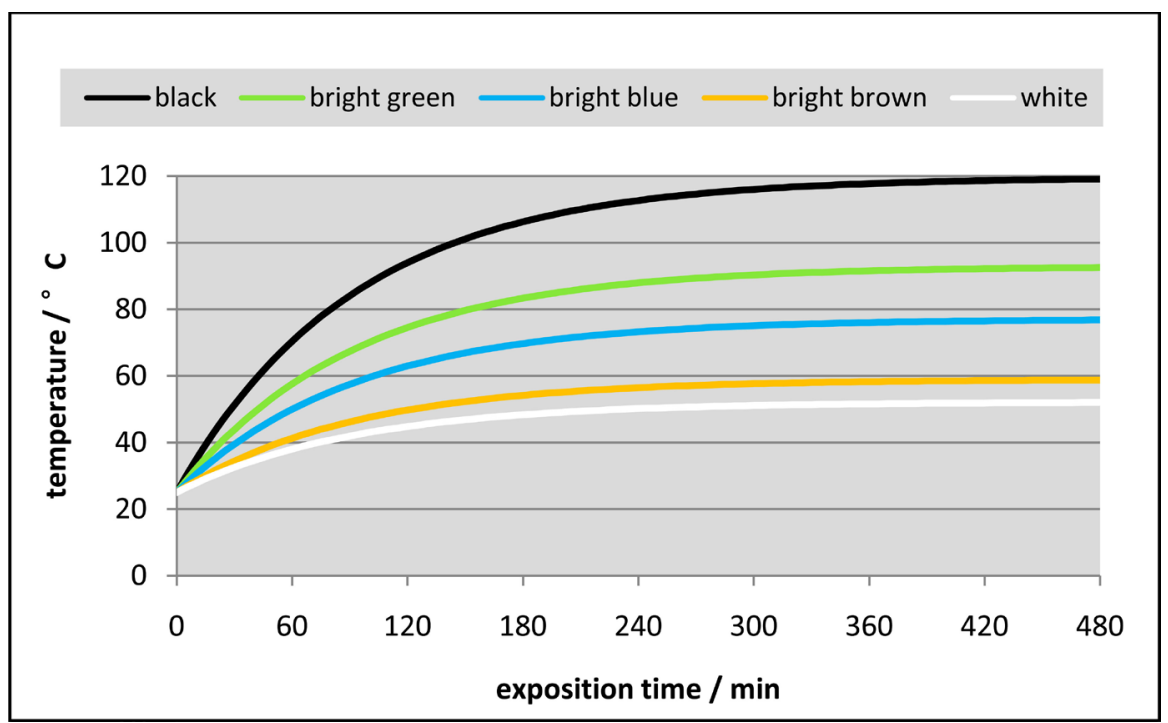

Figure 7. Temperature courses at differently coloured aluminium-plates ( $20 \mathrm{~mm}$ thick).

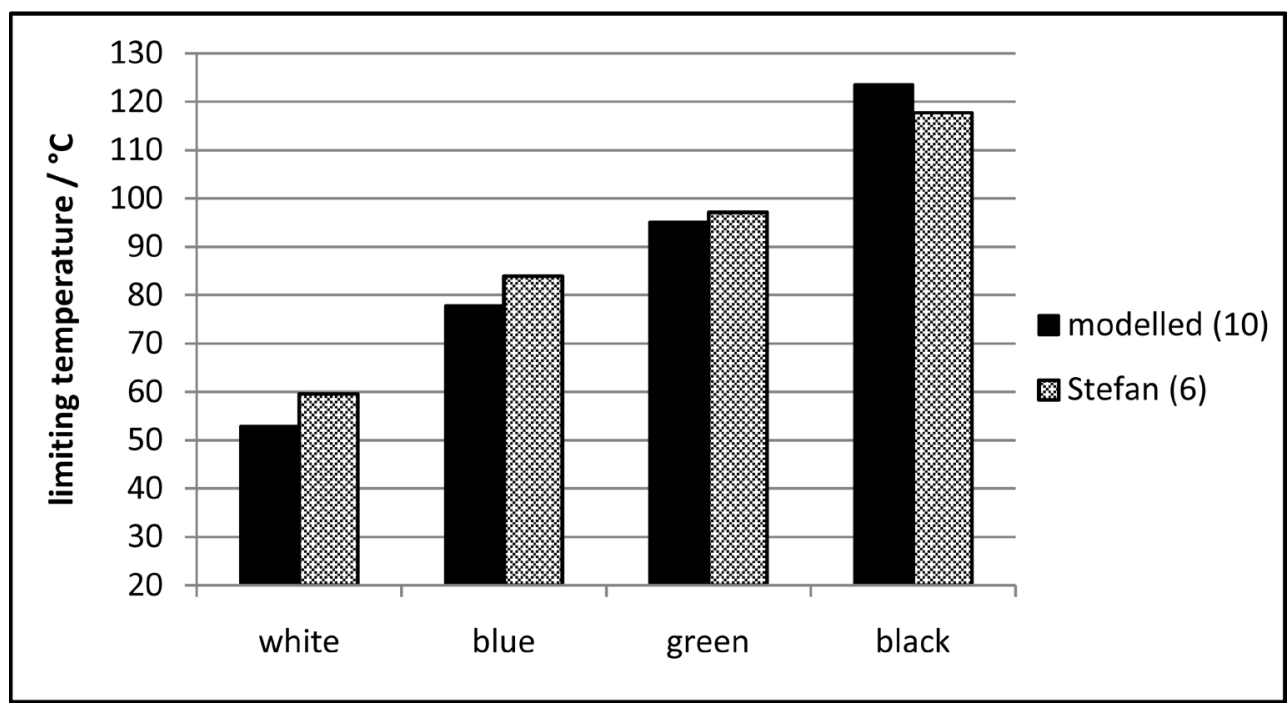

Figure 8. Comparison of the calculated values according to eq. (9) and (6) based on the edge data given in [11] Figure 3. 
open atmosphere. Similarly, the author's own cooling-down experiments, whose results allowed the computational simulation of the limiting temperatures, were made in a closed room. Thus in both cases the counter-radiation might be induced by the surrounding walls, i.e. by solid opaque bodies, and not-or not only-by open air. As a consequence, a stringent empirical proof is solely possible if the coloured plates are irradiated by sunlight as long as their temperatures have reached the limiting values, and this is preferably achieved by using thinner plates with smaller heat capacities. Hence, the first and preliminary purpose of the present treatise consists in delivering experimental data for assessing the modelled values given in [11] by using $8 \mathrm{~mm}$ thick aluminium plates instead of the ones that are $20 \mathrm{~mm}$ thick.

In view of the above alleged objections which, in spite of the apparent evidence, suggest a principal questioning of the Stefan-Boltzmann relation, a second purpose arises consisting in establishing and verifying a hypothesis which immediately suggests itself through a result of a further method which was published recently by the author [14]. It concerns the measurement of IR-absorption and IR-emission by gases and will be shortly described below. Its results promise an application to the atmospheric counter-radiation, which will lead to a modification of the Stefan-Boltzmann relation concerning its air radiation term.

\section{The Basic Work about the IR-Adsorption and IR-Emission by Gases and Its Hypothetical Application to the Atmospheric Radiation}

The starting point of the here referenced author's research [15] was the common greenhouse theory. According to this, the atmosphere is solely warmed-up due to absorption of thermal Earth radiation by so-called greenhouse gases, in particular by carbon-dioxide, while pure air is assumed to be incapable of absorbing any IR(infrared)-radiation, be it the near-IR of the incident solar-radiation (wavelength $\lambda<3 \mu \mathrm{m})$, or the medium-IR of the thermal Earth radiation $(\lambda>3 \mu \mathrm{m})$. At least the former assumption must be questioned in view of the fact that the intensity of the incident solar light is considerably reduced by the atmosphere: As it is well-known, there is a significant difference between the extra-terrestrial solar constant (measured on the top of the atmosphere) and the terrestrial solar constant (measured on the Earth surface). For the extra-terrestrial one, commonly the average value $1360-1366 \mathrm{Wm}^{-2}$ is assumed (see for instance [16] [17]), while for the terrestrial one approximately $1000 \mathrm{Wm}^{-2}$ are measured, but dependant on the altitude (see later). The primary, basic investigations were made with solar light and-particularly-with artificial IR-light exhibiting mainly near-IR [14], while additional measurements concerning thermal radiation, i.e. medium-IR, were carried out with a hotplate [18].

Compared to solid bodies, thermal measurements on gases are much more delicate. Due to their low heat capacity they suggest a considerable interference with the vessel walls in which the gas is embedded, apart from the fact that gases 
may move when a temperature gradient arises. Hence, a large ratio between the gas volume and the surface of the vessel must be intended, as well as a low heat capacity of the vessel material. Therefore, it is not surprising that no effect can be detected when heavy materials and apparatus are used, as it was the case with the photometric measurements made by Tyndall [5] using apparatus shown in Figure 1, or by his followers Arrhenius [19] and Knut Ångström [20], in spite of the fact that no caloric measurements were made but solely photometric ones.

Therefore, the author's experiments were made using very light building materials, namely square tubes from Styrofoam $(3 \mathrm{~cm}$ thick, $1 \mathrm{~m}$ long, outer diameter $25 \mathrm{~cm})$, covered above and below with a thin transparent foil $(0.01 \mathrm{~mm}$ thick Saran-wrap). At an advanced stage, the Styrofoam was sealed with adhesive foils and mirrored with aluminium foils. For the measurements with solar light, one or two tubes were pivoted on a frame so that they could be exactly oriented in the direction of the light (Figure 9). For the measurements with artificial light, an IR-spot with a reflector was mounted above the vertically aligned tube (Figure 10), while for the thermal radiation measurements a hotplate was positioned on the bottom of the tube (Figure 11).

When artificial infrared light or thermal radiation was applied, normally a temperature gradient along the measuring tube appeared, in contrast to the use of solar light which did not exhibit such an intensity decrease (Figure 12). This effect was detected by providing three temperature-measuring points in the distance of $40 \mathrm{~cm}$. In spite of this disadvantage, most measurements were made with artificial light since it enabled higher intensities and better reproducibility. The deviations could be minimized by mounting internal mirroring with aluminium foils along the tube walls. This effect had always been disregarded at former IR-measurements with gases, apart from the fact that not the temperature

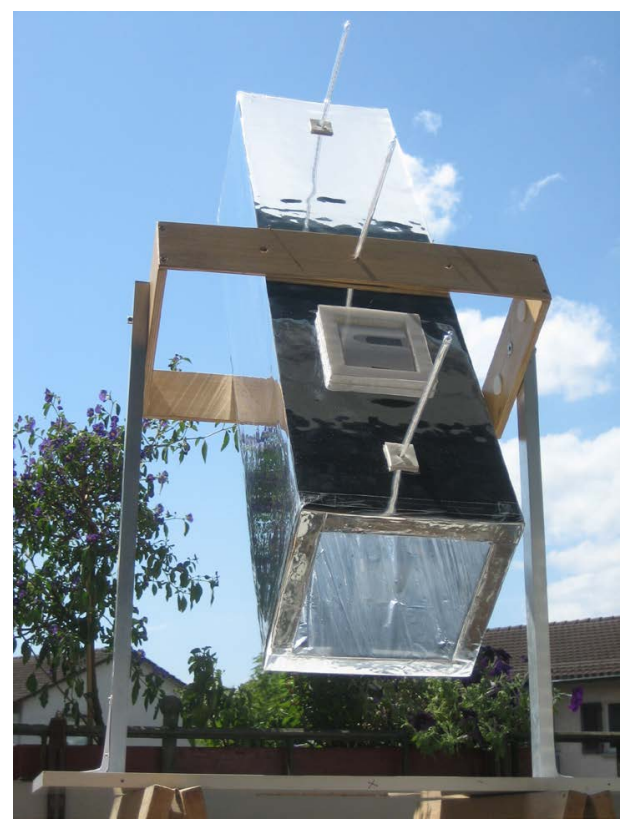

Figure 9. Solar-tube according to [14]. 


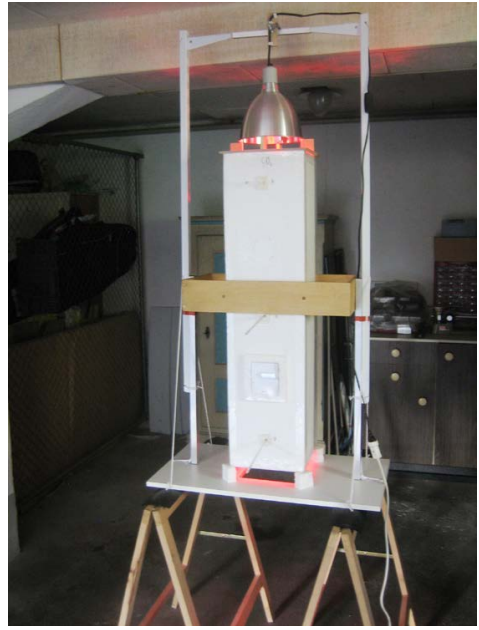

Figure 10. Equipment with IR-lamp according to [14].

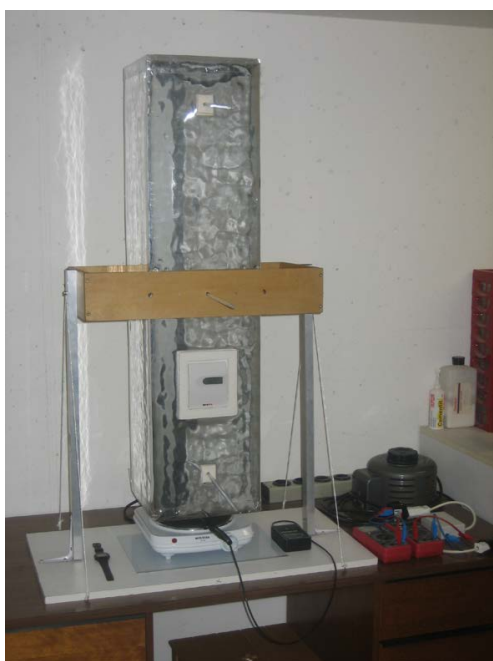

Figure 11. Equipment with hotplate according to [18].

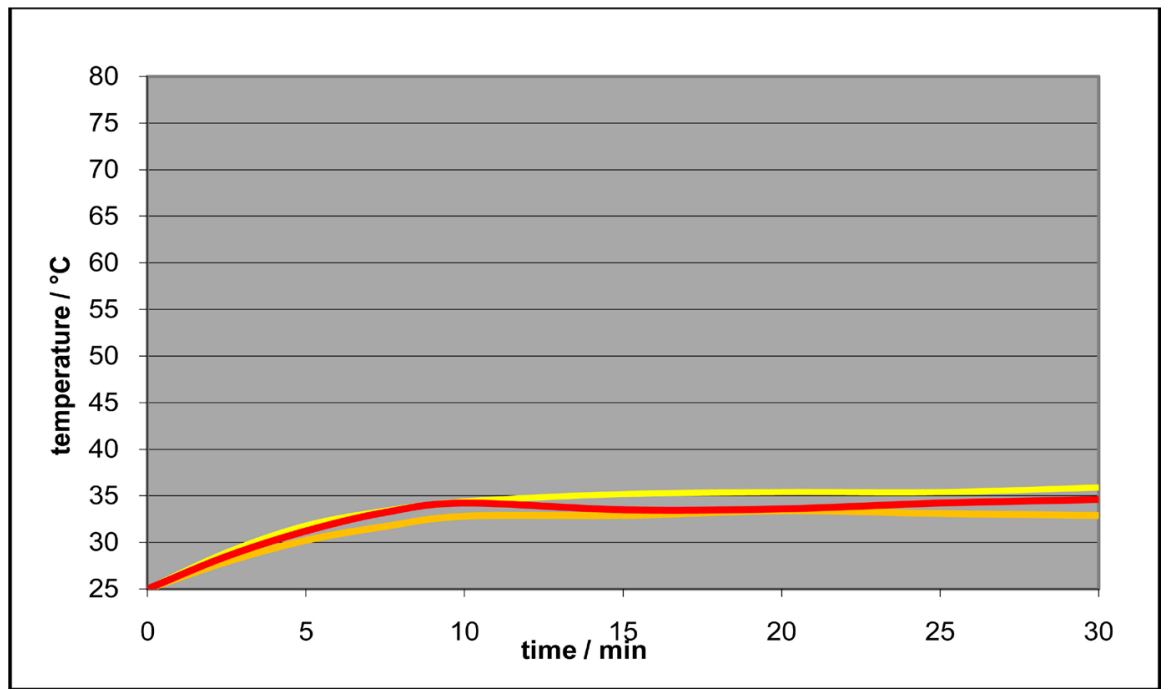

Figure 12. Time/temperature curves for solar light at three different temperature-positions, detected with the solar tube shown in Figure 9. 


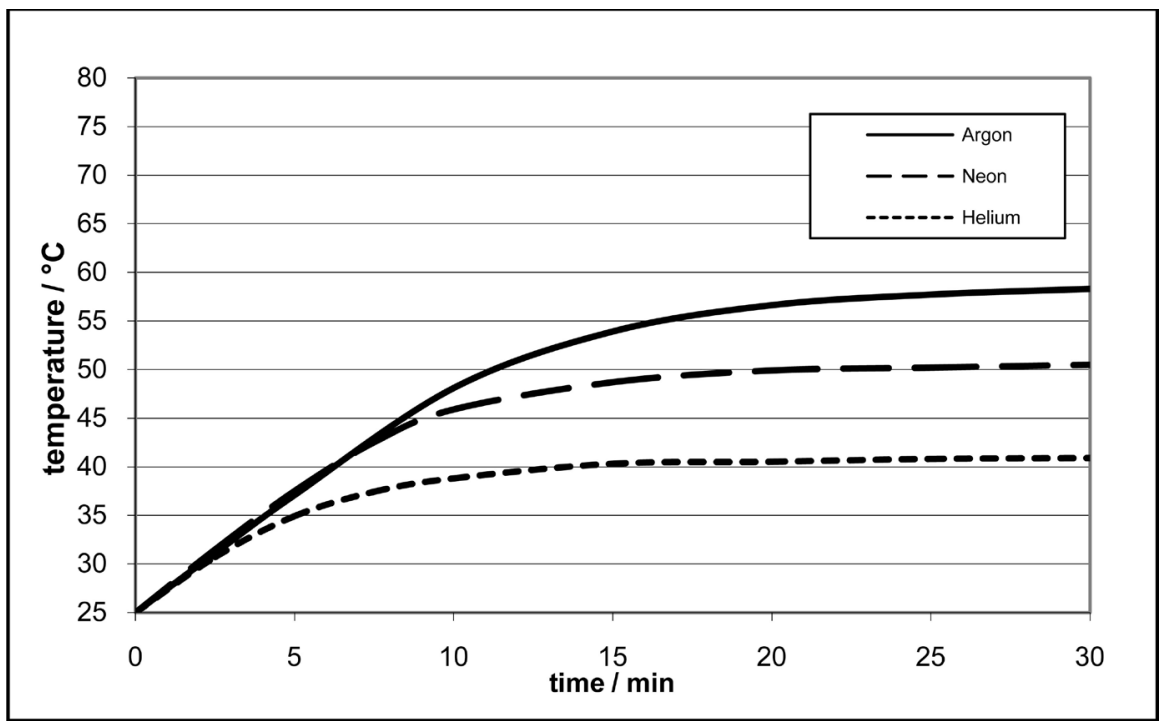

Figure 13. Time-temperature curves of different noble gases (150 W IR-spot, middle thermometer position).

enhancement of the gas was measured but solely the intensity loss of the applied light ray.

The time-temperature curves of irradiated gases proceed alike to those of irradiated SOBs, always reaching limiting temperatures. Analogously, it may be assumed that a limiting temperature is attained when a steady equilibrium exists between the intensity of the absorbed radiation, on the one side, and of the emitted radiation, on the other side. Thus the knowledge of the limiting temperature values enables making statements about the radiation emissivity of the respective gases. Surprisingly, any gas was up-warmed, even noble gases did so (Figure 13), while-contrary to the prediction of the conventional greenhouse theory-no significant difference could be found between pure carbon-dioxide, air and argon. In the case of thermal radiation emitted by a hotplate, comparing air with carbon-dioxide, a similar behaviour was found (Figure 14). However, that test assembly did not permit exact evaluations due to the thermal delay of the hotplate after being switched on.

The interpretation of the results obtained with the IR-spot apparatus enabled the empirical determination of the heat absorbance coefficient of a gas, which turned out to be very low. So it is not surprising, that this effect has been overlooked so far. While a theoretical calculation of such an absorption coefficient was not feasible, at least a principal explanation may be given:

There is no good reason to assume that absorbed IR-radiation will be entirely transformed into heat. Instead, it is conceivable that a part of it is re-emitted, i.e. to say in all directions, before having induced a temperature enhancement. The absorption of infrared light by an atom or a molecule can be explained quantum-mechanically assuming excitations of electrons which are quantized. Vice versa, the radiation emission obeys the same quantum-mechanical regularities. According to the de Broglie hypothesis, such a quantisation is due to the 


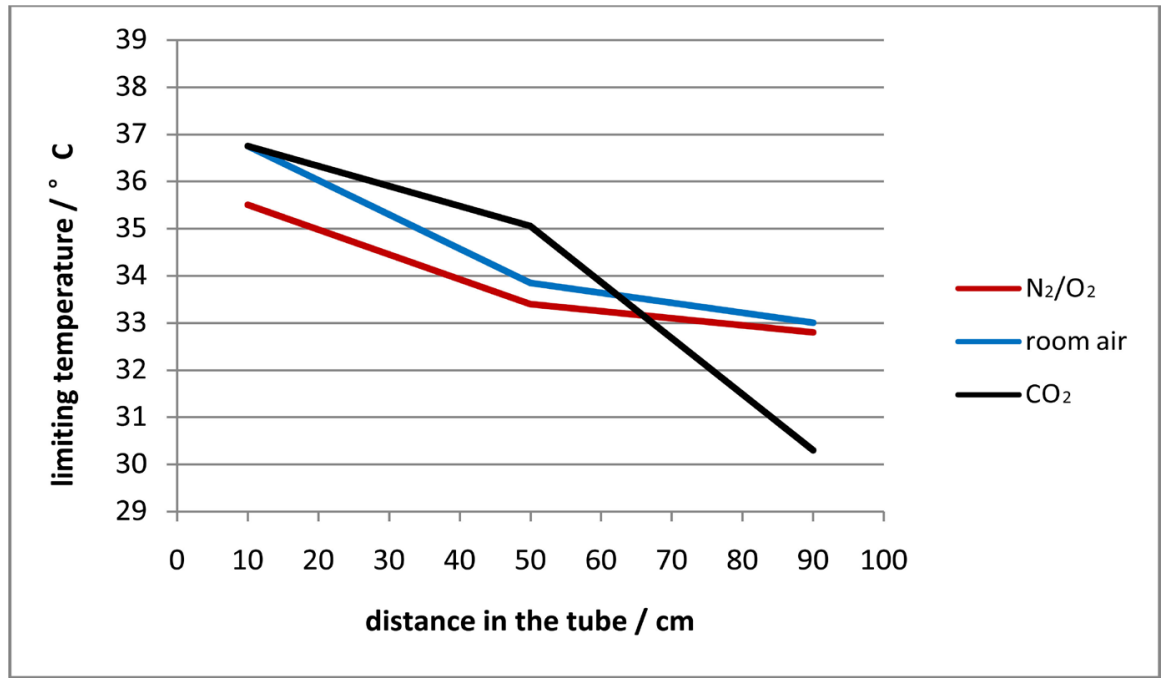

Figure 14. Limiting temperatures for different gases at different positions, average values of two measurements, according to [18] (heat power $37.1 \mathrm{~W}$, initial temperature $23.5^{\circ}$, pressure ca. $1032 \mathrm{hPa}$, humidity 45\% - 55\%).

occurrence of standing electron waves in the excited states. Obviously such phenomena are possible not only at molecules with polar bonds, as is the case at the absorption of medium-IR by $\mathrm{CO}_{2}$ and $\mathrm{H}_{2} \mathrm{O}$-and as it is assumed as the only possible explanation for IR-absorption in the conventional theory-, but also with molecules exhibiting nonpolar bonds, and even at noble gases. So this is an intra-molecular phenomenon. On the other hand, heat is due to the kinetic energy content of the gas which correlates to the translational movement of whole molecules or atoms. So that is an inter-molecular phenomenon. That movement is not quantized and thus it cannot be described quantum-mechanically, but solely by means of the kinetic gas theory. The latter one is well-established, being satisfyingly applied for explaining simple heat-conduction in gases, but so far it has been completely disregarded in atmospheric physics.

Using the kinetic gas theory, it was feasible to explain the ratio of the different limiting temperatures as an implication of the radiative emission. The noble gases argon, neon and helium turned out to be optimal for comparison (Figure 13) since their limiting temperatures differed enough to be interpreted, and since in any case one-atomic gases are involved. Assuming a direct correlation between the limiting temperature and the radiative emission power, a stringent dependency on the product of the mean kinetic energy and the collision frequency could be deduced, namely

$$
\Phi_{\text {emission }} \sim a \cdot M^{-0.5} \cdot T^{0.5} \cdot p
$$

( $a=$ cross sectional area, $M=$ atomic mass, $T=$ absolute temperature, $p=$ pressure)

When the heating-up rates are equal, the comparison of two gases yields for the relevant absolute limiting temperatures $T_{1}$ and $T_{2}$ the relation

$$
T_{1} / T_{2}=M_{1}\left(r_{2}\right)^{4} / M_{2}\left(r_{1}\right)^{4}
$$


where $M_{1}$ and $M_{2}$ indicate the atomic masses, and $r_{1}$ and $r_{2}$ the atomic radii of the compared gases. This relation could be empirically verified with the data of helium, neon and argon.

Moreover, a rough estimate of the effective wavelength-range was possible by comparing the absorbance rates at sunlight and at artificial light, delivering the value of approx. $1.9 \mu \mathrm{m}$. Finally, the calculation of the radiative heat coefficient yielded that the amount of radiative energy being transformed into kinetic heat energy is very small. Therefore, the empiric evidence was delivered that any gas is warmed up to a limiting temperature by near-infrared light as well as by sunlight.

As a consequence, it stands to reason that a principal dependency on the radiative emission intensity of a gas on the product of its mean kinetic energy and the collision frequency exists. This suggests a general application to any thermo-radiative emission process of gases-and thus likewise to atmospheric air-, delivering a hypothesis for the wanted term $f\left(p_{\text {atm }}, T_{\text {atm }}\right)$ in relation (8). Since the cross sectional areas as well as the molecular masses of the main air components nitrogen and oxygen are similar, Equation (11) can be simplified delivering the expression

$$
\Phi_{\text {emission }}=A \cdot T^{0.5} \cdot p
$$

whereby $A$ represents a constant which has to be empirically determined. It may be called "atmospheric emission constant". Hence the modified Stefan-Boltzmann relation would be written

$$
\Phi \cdot \beta_{\mathrm{s}}=\sigma \cdot T_{\mathrm{SOB}, \mathrm{lim}}^{4}-A \cdot T_{\mathrm{atm}}^{0.5} \cdot p_{\mathrm{atm}}
$$

or rearranged

$$
\sigma \cdot T_{\mathrm{SOB}, \mathrm{lim}}^{4}=\Phi \cdot \beta_{\mathrm{s}}+A \cdot T_{\mathrm{atm}}^{0.5} \cdot p_{\mathrm{atm}}
$$

yielding the expression

$$
A=\frac{\sigma \cdot T_{\mathrm{SOB}, \mathrm{lim}}^{4}-\Phi \cdot \beta_{\mathrm{s}}}{p_{\mathrm{atm}} \cdot T_{\mathrm{atm}}^{0.5}}
$$

In order to verify this hypothetical relation and to determine the constant $A$, measurements were made at different altitudes for varying the atmospheric pressure applying the above mentioned method, but using thinner aluminium plates which allowed to directly determine the limiting temperatures.

\section{Equipment and Locations for the Present Investigation}

In order to verify the Stefan-Boltzmann relation as well as the own modelling method described in chap. 2 according to [11], the original equipment (Figure 3 and Figure 4) had to be modified using $8 \mathrm{~mm}$ thick aluminium plates instead of $20 \mathrm{~mm}$ thick ones. They enabled to reach the limiting temperature within a shorter time (approx. in one and a half hours, instead of more than three hours). However, the lower heat capacity of the thinner plates entailed the disadvantage 
of a higher thermal interference in the embedding Styrofoam modules, as well as of heat losses due to ambient air convection, particularly at high plate-temperatures. The plates were painted with the same colours which had been applied within the original experiments; however, solely four colour types were used, namely white, light blue, light green, and black. The intensity of the solar radiation (given in $\mathrm{Wm}^{-2}$ ) was measured by an electronic KIMO “Solarmeter" SL 100. For comparison, the results of the original measurements with $20 \mathrm{~mm}$ thick aluminium plates were quoted.

In order to verify the hypothetical formal approach $(14,15)$ by studying the influence of the atmospheric pressure, measurements were made at two different locations: in Glattbrugg (near Zürich, Switzerland), $430 \mathrm{~m}$ above sea level, and on the top of the Furka-Pass (Switzerland), $2430 \mathrm{~m}$ above sea level. The atmospheric pressure was not measured but checked by official data of the respective weather stations. However, it should be known that, from meteorological reasons, such data do not concern real pressure values but only normalized ones, being formally converted to the values at sea-level (zero). But since the meteorological pressure variations are negligibly low compared to the pressure variations due to significant altitude variations of locations, the here relevant pressure values have solely been calculated using the usual barometric height formula (15),

$$
p=p_{0} \mathrm{e}^{-\frac{\rho_{0} \cdot g \cdot h}{p_{0}}} \cong p_{0} \mathrm{e}^{-\frac{h}{8 \mathrm{~km}}}
$$

$\rho_{0}=$ density of the air, $g=$ gravity constant, $p_{0}=$ pressure at sea level $(1$ bar $), h=$ altitude delivering the values of 0.948 bar for Glattbrugg, and 0.738 bar for the top of the Furka-Pass. Between the $20^{\text {th }}$ June and the $5^{\text {th }}$ July 2017, altogether four useable measurements were made, two in Glattbrugg and two on the top of the Furka-Pass, letting suppose only minimal differences in the characteristics of the solar radiation. The comparative measurements with $20 \mathrm{~mm}$ thick aluminium plate had been made on 4 Sept. 2013 in Glattbrugg, hence approx. two months later (Figure 5).

As already mentioned, atmospheric pressure and temperature as well as intensity of the solar irradiation are not independent of each other, so it is not possible to vary solely the atmospheric pressure by relocating. However, the here proposed approach implies the different influences of the three parameters, in contrast to the Stefan-Boltzmann relation.

Since the measurements had to last till the limiting temperatures had been attained, it was unavoidable that the ambient air temperature increased during the exposure time of one and a half hours, due to permanent sunshine. So the ambient air temperature was not well defined. However, this was of much less consequence with respect to the numerical verification of the alternative approach (14) than with respect to the one of the Stefan-Boltzmann relation (5) since the exponential dimension of $T_{\mathrm{am}}$ is in the former case much lower, namely 0.5 instead of 4 . 


\section{Results, Interpretation and Conclusions}

As already mentioned, the measurements were made between the end of June and the beginning of July 2017, alternatingly in the low-lying Glattbrugg and on the high-lying Furka-Pass, and usually starting midday. During that whole summer the weather was windy and variable: Even when the sky was clear it was often accompanied by small scattered clouds-perhaps as a result of climate change-, which made it difficult to find dates where the conditions were suited for measurements. Although the experiments were not perfect in every case, they delivered nevertheless satisfying results.

Obviously, the starting conditions for the two kinds of measurements were quite different: While in the low-lying Glattbrugg the starting temperature was considerably higher than on the high-lying Furka-Pass (on average $27^{\circ} \mathrm{C}$, compared to $17^{\circ} \mathrm{C}$ ), the solar radiation intensity was higher on the high-lying Furka-Pass, due to the thinner atmosphere layer (on average $1210 \mathrm{Wm}^{-2}$, compared to $1075 \mathrm{Wm}^{-2}$ ). As is generally known, the portion of UV-light is larger in the mountains. Surprisingly, the limiting temperatures for the blackened plates were similar in both cases (cf. Figure 15 and Figure 16), which may be due to an UV-effect. Detailed information about the test conditions is given in Table 1.

In Figure 17 the actual results of the solar adsorption coefficients are compared with the results which have originally been obtained using $20 \mathrm{~mm}$ thick aluminium-plates (according to [11]; measuring date 4 Sept 2013, start 12:40 p.m., $1045 \mathrm{Wm}^{-2}$ ). In spite of some deviations, the value-patterns are quite similar. The tendency of getting higher values for the thicker plates may be explained by their higher heat capacity, allowing the expectation of smaller interferences in the module material. The larger deviations for darker colours, in particular for the black coloured plates, may be explained by the reduced insolation within the modules at higher temperatures. Moreover, the different times of year when the

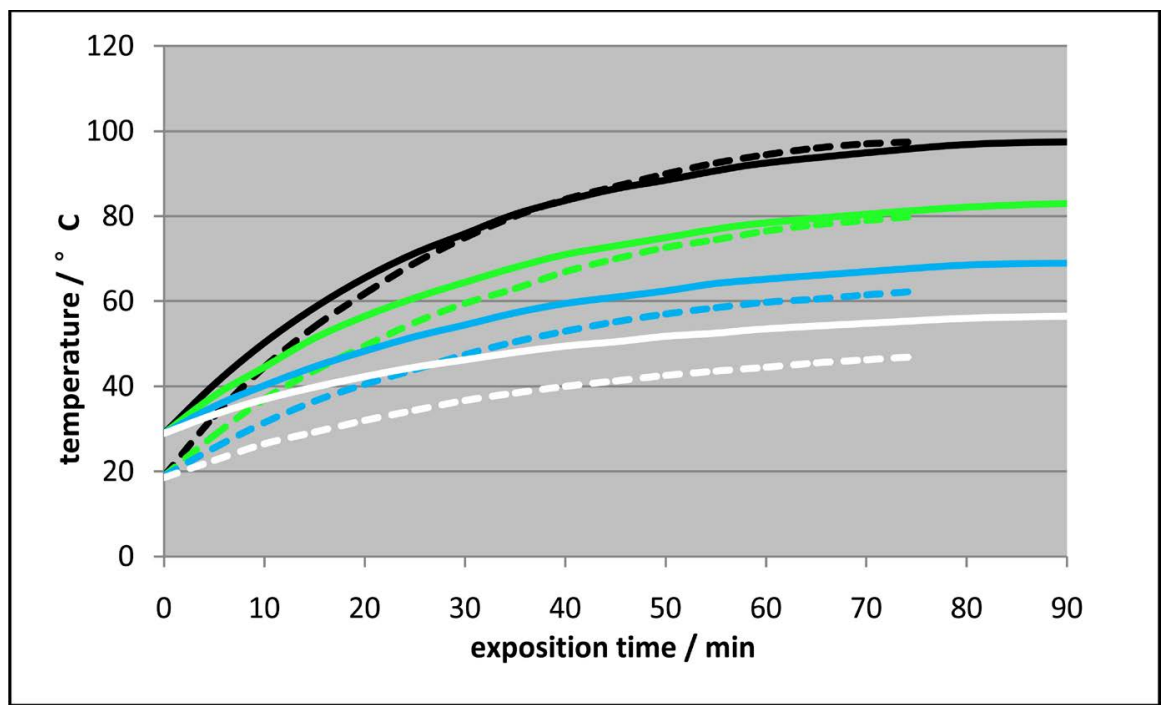

Figure 15. Comparison of the temperature courses during the first two measurements (continuous lines: Glattbrugg 1; dotted lines: Furka 1). 


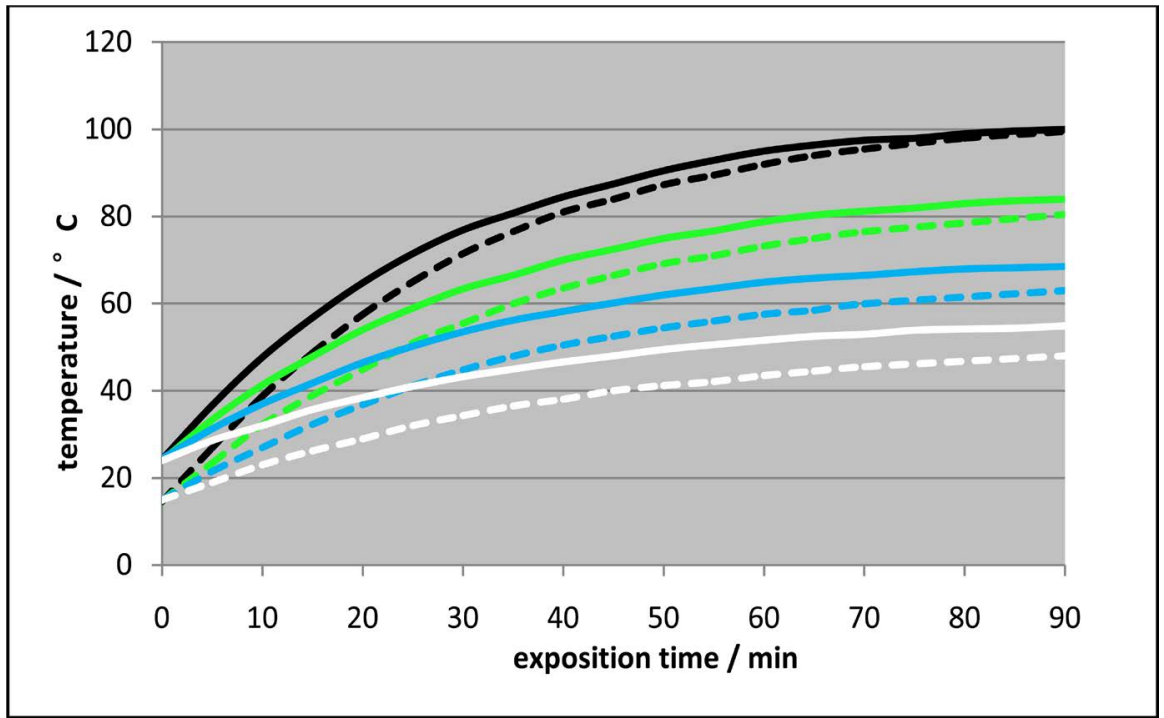

Figure 16. Comparison of the temperature courses during the second two measurements (continuous lines: Glattbrugg 2; dotted lines: Furka 2).

Table 1. Calculated $A$-values.

\begin{tabular}{|c|c|c|c|c|c|c|c|}
\hline $\begin{array}{l}\text { Location } \\
\text { Exp.-no. }\end{array}$ & $\begin{array}{l}\text { Date } \\
(2017)\end{array}$ & $\begin{array}{c}\text { Start } \\
{[\mathrm{h}]}\end{array}$ & $\begin{array}{l}\text { Start-temp } \\
\quad=t_{\mathrm{atm}}\end{array}$ & $\begin{array}{l}\text { End-intensity } \\
{\left[\mathrm{Wm}^{-2}\right]}\end{array}$ & $t_{\text {lim }} / A$ white $t_{\text {lim }} / A$ blue & $t_{\text {lim }} / A$ green & $t_{\text {lim }} / A$ black \\
\hline G8 a & 20 June & $13: 29$ & $29.0^{\circ} \mathrm{C}$ & 1095 & $56.5^{\circ} \mathrm{C} / 22.869 .0^{\circ} \mathrm{C} / 22.5$ & $583.0^{\circ} \mathrm{C} / 20.8$ & $97.8^{\circ} \mathrm{C} / 17.2$ \\
\hline G8 b & 4 July & $12: 46$ & $24.3^{\circ} \mathrm{C}$ & 1065 & $54.9^{\circ} \mathrm{C} / 25.768 .5^{\circ} \mathrm{C} / 20.7$ & $784.0^{\circ} / 23.6$ & $100^{\circ} \mathrm{C} / 22.4$ \\
\hline F8 a & 26 June & $13: 01$ & $18.9^{\circ} \mathrm{C}$ & 1260 & $47.0^{\circ} \mathrm{C} / 26.462 .4^{\circ} \mathrm{C} / 24.3$ & $380.0^{\circ} \mathrm{C} / 22.1$ & $99.5^{\circ} \mathrm{C} / 12.9$ \\
\hline F8 b & 5 July & $12: 42$ & $14.8^{\circ} \mathrm{C}$ & 1210 & $48.0^{\circ} \mathrm{C} / 25.963 .0^{\circ} \mathrm{C} / 21.2$ & $280.5^{\circ} \mathrm{C} / 20.0$ & $97.5^{\circ} \mathrm{C} / 17.3$ \\
\hline
\end{tabular}

Explications: First column: $\mathrm{G}=$ Glattbrugg, $\mathrm{F}=$ Furka-Pass; $\mathrm{a}$ or $\mathrm{b}$ means "experiment-number". The $A$-values are listed in the last four columns, unit $\mathrm{Wm}^{-2} \mathrm{bar}^{-1} \mathrm{~K}^{-0.5}$.

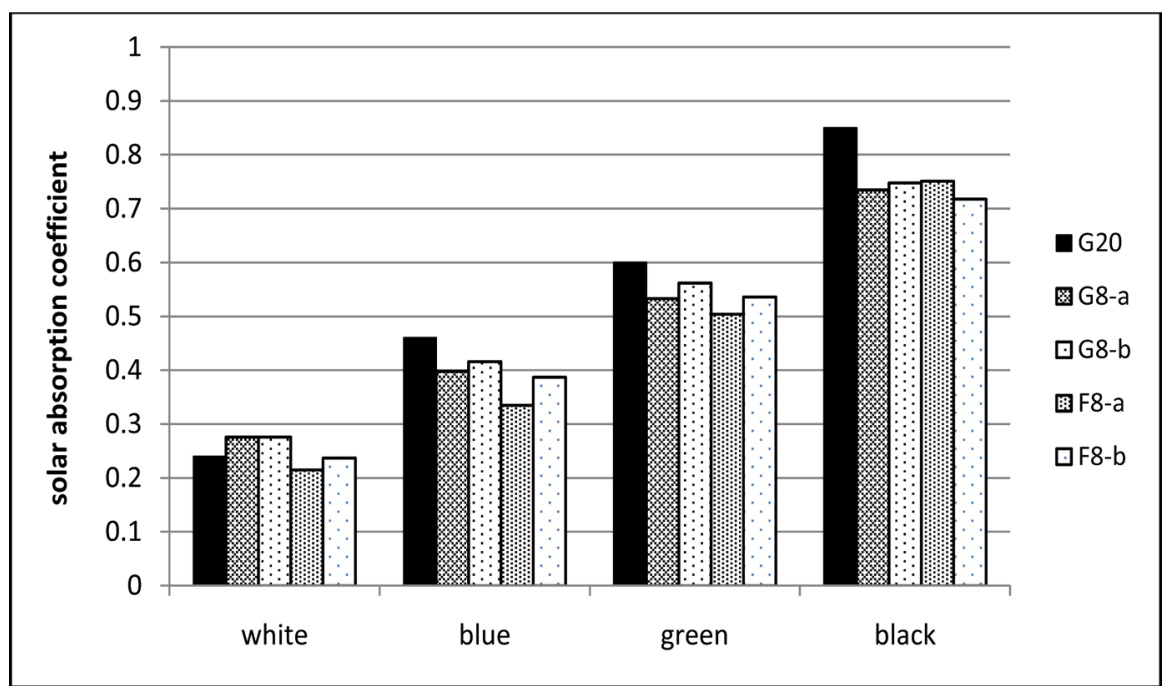

Figure 17. Comparison of solar absorption coefficients determined by five different measurements (Abbreviations: Location/plate thickness in $\mathrm{mm}$-experiment number; locations: $\mathrm{G}=$ Glattbrugg, $\mathrm{F}=$ Furka-Pass). 
measurements were made may have a certain influence due to the different incident angle of the solar light effecting its spectral dispersion.

In Figure 18 the measured limiting temperatures are displayed. Obviously, this pattern is very similar to the pattern of the respective solar adsorption coefficients displayed in Figure 19. It empirically verifies the assertion of Equation (10) that the limiting temperatures are proportional to the solar adsorption coefficients. Moreover, the reproducibility of the respective values is illustrated.

In Figure 19 the measured limiting temperature values are compared with the computed values based on the Stefan-Boltzmann relation. This means that the real counter-radiation of the atmosphere is slightly weaker than the assumed one in the Stefan-Boltzmann relation. Therefore, according to these results, the

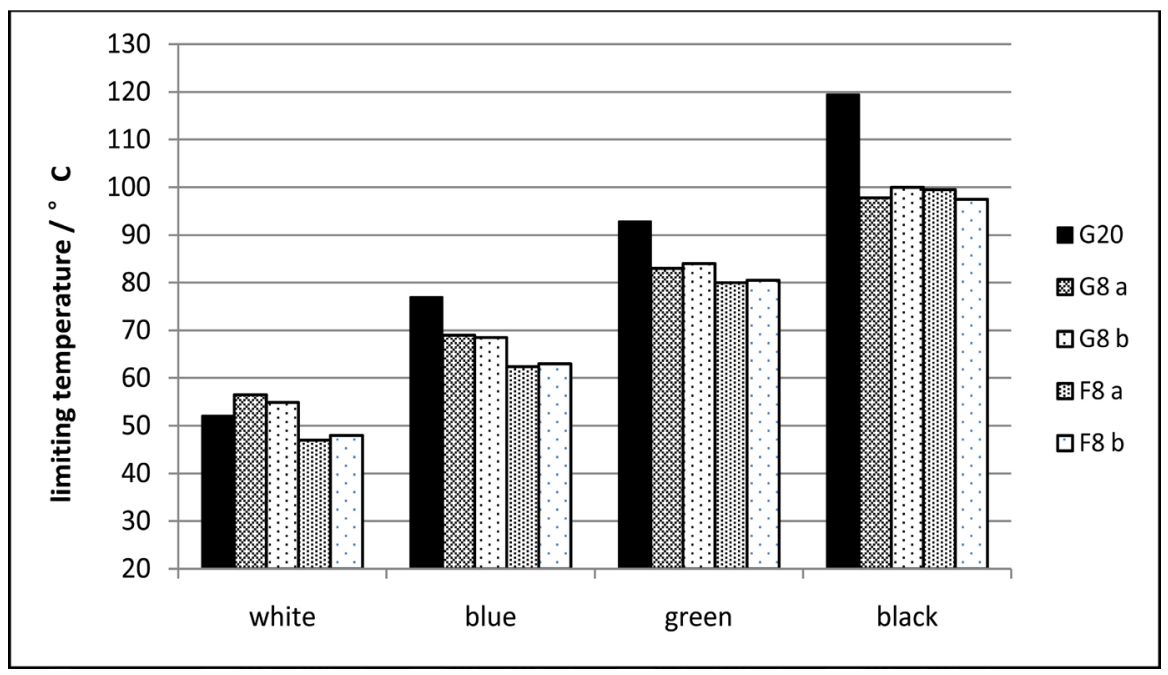

Figure 18. Comparison of the limiting temperatures modelled (G20) and determined by four different measurements (Abbreviations: location/plate thickness in $\mathrm{mm}$-experiment number a or b; locations: $\mathrm{G}=$ Glattbrugg, $\mathrm{F}=$ Furka-Pass).

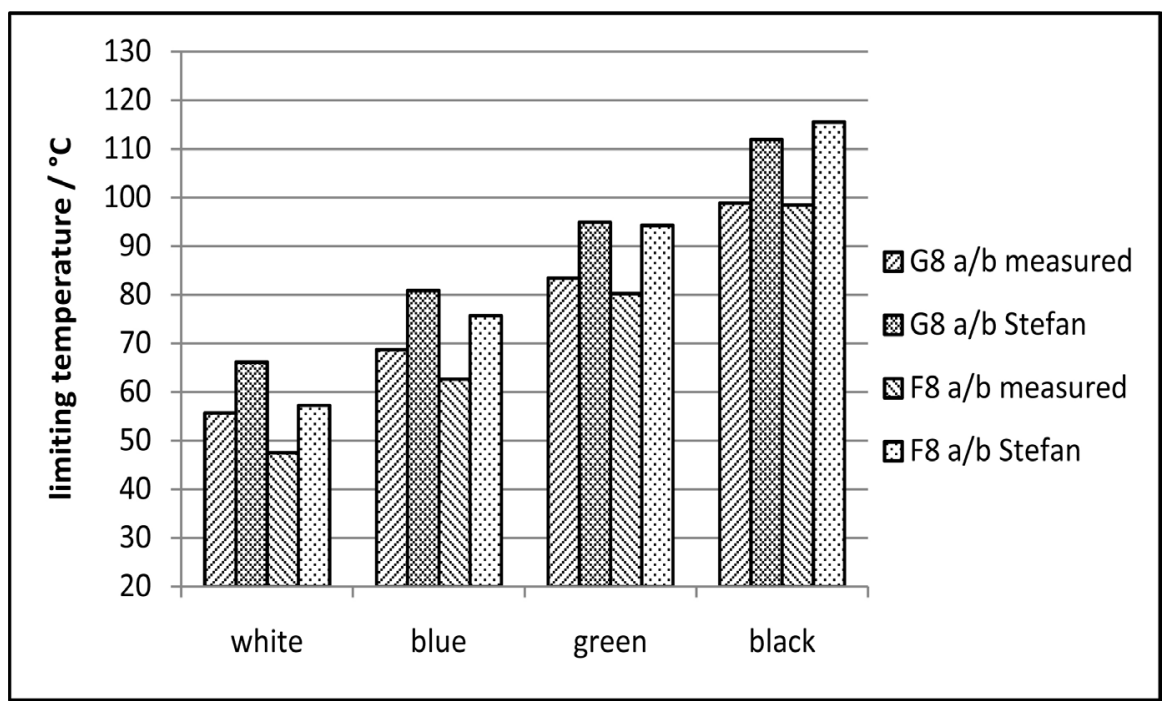

Figure 19. Comparison of the mean limiting temperatures of $8 \mathrm{~mm}$ thick plates, measured and calculated according to Stefan for Glattbrugg (G8 a/b) and for Furka (F8 a/b). 
Stefan-Boltzmann relation is fulfilled to a certain extent, but not precisely.

Finally, and above all, these results can be used for the verification in the alternative approach given by the formulas (13)-(15). In Table 1, the calculation results for the atmospheric emission constant $A$ are listed, using formula (15). In view of the intricate measurement conditions, they coincide satisfyingly, in particular with respect to the results obtained with the colours light-blue and light-green, yielding an approximate average value of $A=22 \mathrm{Wm}^{-2} \mathrm{bar}^{-1} \cdot \mathrm{K}^{-0.5}$. As a consequence, the relation (14a, b) is verified as a general natural law, even if the value of the atmospheric emission constant $A$ may slightly vary, also depending on the atmospheric conditions.

This means that for the counter-radiation solely the lowest layer of the atmosphere-or the boundary layer of the Earth surface-is relevant, characterized by its temperature and-especially-by its pressure. Obviously, at lower atmospheric pressures the increase of solar irradiation, which is due to a reduced absorption within the atmosphere, is over-compensated by the decrease of counter-radiation due to the pressure loss. In the absence of solar irradiation, analogously to Equation (7) the thermal emission power of the soil can be expressed by formula (17):

$$
\Phi_{\text {emission,soil }}=\sigma \cdot T_{\text {soil }}^{4}-A \cdot p_{\text {atm }} \cdot T_{\text {atm }}^{0.5}
$$

When $T_{\text {atm }}=T_{\text {soil }}$, i.e. at a steady equilibrium state, $T$ becomes $283.3 \mathrm{~K}=10^{\circ} \mathrm{C}$ for $p_{\text {atm }}=1$ bar. However, normally no radiative equilibrium exists at the Earth surface but rather a gradient. As a consequence, on mountains the cooling down of the Earth surface is accelerated, compared to the one on lowlands. This mainly explains the temperature decrease on mountains, even if additionally thermodynamic effects due to rising air and to horizontal wind-convection are relevant, besides the radiative heat transfer between the atmosphere and the Space.

This approach contradicts in many ways the conventional greenhouse theory: Firstly, the boundary processes at the Earth surface and at the lowest layer of the atmosphere are predominant, while the conventional greenhouse theory regards the whole atmosphere; and secondly-even more crucial-the radiation budged is solely determined by the air conditions of the atmosphere such as pressure and temperature while so-called "greenhouse gases" such as carbon-dioxide do not have the slightest influence on the climate. Besides, the atmosphere cannot really be compared to a greenhouse, not least due to the absence of a glass-roof which absorbs IR-radiation, and which inhibits considerable air convection. Further objections are delivered in [18].

However, the atmosphere certainly plays a decisive part in enabling life on Earth. On the one hand it acts as insulation, absorbing hazardous radiation such as UV (by ozone), and on the other hand it keeps the heat of the Earth surface which is delivered by the sun. Presently, mankind fears that heat events become more frequent and severe. As a result of these considerations, brightening of the Earth surface-preferably of roofs and of buildings in cities [21] -is the only promising remedy for mitigating the climate and reducing the superficial pres- 
sure gradients which are responsible for storms, while the conventional greenhouse theory has definitively proved to be fallacious and should be abandoned.

\section{Acknowledgements}

The present work has been carried out independently but not without the critical support of Dr Andreas Rüetschi and the translation assistance of Verena Ginobbi.

\section{References}

[1] Planck, M. (1900) Ueber Irreversible Strahlungsvorgänge. Annals of Physics, 306, 69-116. https://doi.org/10.1002/andp.19003060105

[2] Planck, M. (1900) Entropie und Temperatur strahlender Wärme. Annals of Physics, 306, 719-737. https://doi.org/10.1002/andp.19003060410

[3] Planck, M. (1900) Zur Theorie des Gesetzes der Energieverteilung im Normalspectrum. Verhandlungen der Deutschen physikalischen Gesellschaft, 2, 237-245.

[4] Beer, A. (1852) Bestimmung der Absorption des rothen Lichts in farbigen Flüssigkeiten. Annalen der Physik, 62, 78-88.

[5] Tyndall, J. (1861) On the Absorption and Radiation of Heat by Gases and Vapours, and on the Physical Connexion of Radiation, Absorption, and Conduction. Philosophical Magazine and Journal of Science, 22, 169-194 and 273-285. https://doi.org/10.1098/rstl.1861.0001

[6] Stefan, J. (1879) Über die Beziehung zwischen der Wärmestrahlung und der Temperatur. Sitzungsberichte der Kaiserlichen Akademie der Wissenschaften in Wien, Vol. 79, Aus der k.k. Hof-und Staatsdruckerei, 391-428.

[7] Dulong, M.M. and Petit (1817) Des Recherches sur la Mesure des Températures et sur les Lois de la communication de la chaleur. Annales de Chimie et de Physique, 2, 225-264 ("Des Lois du Refroidissement") and 337-367 ("Du Refroidissement dans l'air et dans les gaz").

[8] Lummer, O. und Pringsheim, E. (1899) Die Verteilung der Energie im Spektrum des schwarzen Körpers. Verhandlungen der Deutschen Physikalischen Gesellschaft, 1, 23-41.

[9] Boltzmann, L. (1884) Ableitung des Stefan'schen Gesetzes betreffend die Abhängigkeit der Wärmestrahlung von der Temperatur aus der electromagnetischen Lichtheorie. Annalen der Physik und Chemie, 22, 291-294. https://doi.org/10.1002/andp.18842580616

[10] Meschede, D. (2002) Gerthsen Physik. Springer, Berlin, 21. https://doi.org/10.1007/978-3-662-07460-2

[11] Allmendinger, T. (2016a) The Solar-Reflective Characterization of Solid Opaque Materials. International Journal of Science and Technology Educational Research, 7, 1-17. https://doi.org/10.5897/IJSTER2015.0341 http://www.academicjournals.org/journal/IJSTER/article-full-text-pdf/E7435F75915 $\underline{8}$

[12] Kirchhoff, G. (1860) Ueber das Verhältnis zwischen dem Emissionsvermögen und dem Absorptionsvermögen der Körper für Wärme und Licht. Annals of Physics, 109, 275-301. https://doi.org/10.1002/andp.18601850205

[13] Kirchhoff, G. (1861) On a New Proposition in the Theory of Heat. Philosophical Magazine, 21, 241-247. 
[14] Allmendinger, T. (2016) The Thermal Behaviour of Gases under the Influence of Infrared-Radiation. International Journal of Physical Sciences, 11, 183-205. http://academicjournals.org/journal/IJPS2016/article-full-text-pdf/E00ABBF60017

[15] Allmendinger, T. (2017) A Novel Investigation about the Thermal Behaviour of Gases under the Influence of IR-Radiation: A Further Argument against the Greenhouse Thesis. Journal of Earth Science \& Climatic Change, 8, 393.

https://www.omicsonline.org/open-access/a-novel-investigation-about-the-thermal -behaviour-of-gases-under-theinfluence-of-irradiation-a-further-argument-againstthe-greenh-2157-7617-1000393.php?aid=87335

[16] Visconti, G. (2001) Fundamentals of Physics and Chemistry of the Atmosphere. Springer, Berlin. https://doi.org/10.1007/978-3-662-04540-4

[17] Boeker, E.G. and van Grondelle, R.I. (2011) Environmental Physics. 3rd Edition, John Wiley \& Sons Ltd., Hoboken. https://doi.org/10.1002/9781119974178

[18] Allmendinger, T. (2017) The Refutation of the Climate Greenhouse Theory and a Proposal for a Hopeful Alternative. Environment Pollution and Climate Change, 1, 123.

https://www.omicsonline.org/open-access/the-refutation-of-the-climate-greenhous e-theory-and-a-proposal-for-ahopeful-alternative.php?aid $=88698$

[19] Arrhenius, S. (1896) On the Influence of Carbonic Acid in the Air upon the Temperature of the Ground. Philosophy Magazine, 41, 238-276.

[20] Ångström, K. (1901) Ueber die Abhängigkeit der Absorption der Gase, besonders der Kohlensäure, von der Dichte. Annalen der Physik, 311, 163-173. https://doi.org/10.1002/andp.19013110913

[21] Allmendinger, T. (2017) Measures at Buildings for Mitigating the Microclimate. Environment Pollution and Climate Change, 1, 128.

https://www.omicsonline.org/open-access/measures-at-buildings-for-mitigating-the -microclimate-2573-458X-1000128.php?aid=90625 https://doi.org/10.4172/2573-458X.1000128 